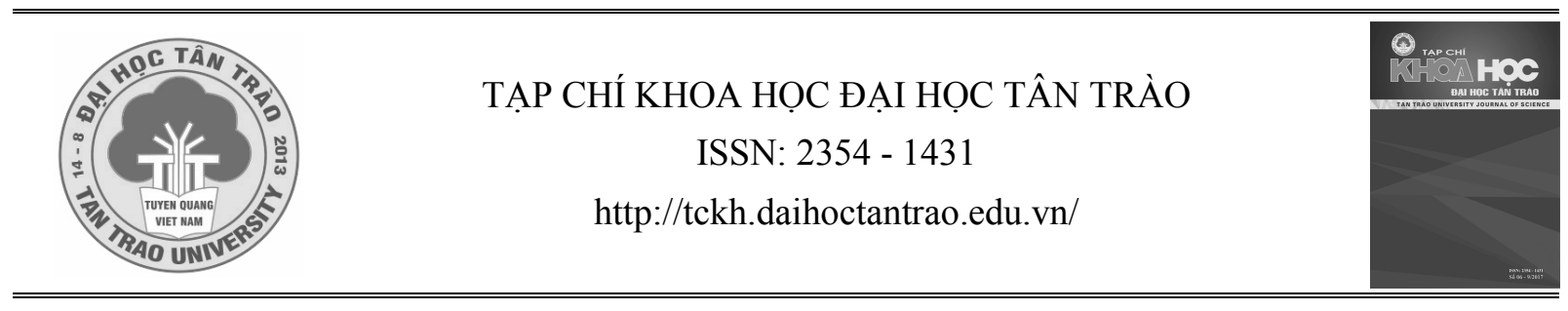

\title{
Chương trình đào tạo giáo viên tập trung vào năng lực
}

\author{
Đặng Thành Hưng ; Nguyễn Khải Hoàn ${ }^{b}$ * \\ ${ }^{a}$ Viên Khoa hoc Giáo duc Việt Nam \\ ${ }^{b}$ Truòng Đại họ Tân Trào \\ *Email: hoannk63@gmail.com
}

\section{Thông tin bài viết}

Ngày nhận bài:

06/02/2018

Ngày duyệt đăng:

$10 / 3 / 2018$

\section{Tù̀ khoá:}

Năng lục;

chuong trinh;

đào tạo giáo viên.

\section{Tóm tắt}

Vấn đề phát triển chương trình đào tạo giáo viên mầm non, tiểu học và trung học cơ sở không phải là mới ở các cơ sở đào tạo giáo viên. Song, đào tạo giáo viên vẫn tồn tại rất nhiều vấn đề nan giải, đặc biệt là năng lực nghề nghiệp sau đào tạo không rõ ràng. Bài viết này góp phần làm sáng tỏ nội dung năng lực nghề dạy học, định hướng tổ chức chương trình và hoạt động đào tạo tập trung vào năng lực.

\section{1. Đặt vấn đề}

Đào tạo tập trung vào năng lực cần được hiểu và thực hiện triệt để hơn cách nói kiểu thời thượng và hình thức. Nói gọn lại, việc đào tạo giáo viên hiện nay không dừng lại ở lí thuyết chung chung về phát triển năng lực mà phải được chuyển hóa thành chương trình và phương pháp tổ chức đào tạo cụ thể mới tạo ra được đội ngũ giáo viên có năng lực nghề nghiệp rõ ràng, có tính chuyên nghiệp cao. Việc xác định mục tiêu đào tạo theo hướng phát triển năng lực nhưng vẫn bám vào chuẩn đầu ra không đo được năng lực, vẫn duy trì cách dạy và đánh giá không nhằm vào năng lực, với các nguồn học liệu không liên quan nhiều đến phát triển năng lực thì không thể có được kết quả như mong muốn. Tuy nhiên, hiện nay các cơ sở đào tạo giáo viên mầm non, tiểu học và trung học cơ sở nói chung còn gặp rất nhiều trở ngại trong đào tạo, từ chương trình, học liệu đến phương pháp dạy học và đánh giá theo định hướng phát triển năng lực. Những khó khăn này đều có nguồn gốc từ nhận thức lí luận.

\section{Nội dung}

\subsection{Năng lục nghề dạy học}

Đào tạo giáo viên là đào tạo nghề dạy học. Vậy khi phát triển chương trình đào tạo phải xác định rất rõ năng lực nghề dạy học là gì. Điều này không rõ ràng lâu nay. Ngay trong các Chuẩn nghề nghiệp giáo viên đã ban hành cũng không rõ khái niệm này. Trong khung chương trình cũng thường xác định thiếu thuyết phục. Chẳng hạn những lĩnh vực đào tạo làm điều kiện để học nghề thì lại gọi là chuyên môn như toán, khoa học, tin học, ngoại ngữ... còn những lĩnh vực đào tạo chuyên môn của nghề, chính là năng lực hành nghề thì lại gọi là nghiệp vụ. Trên thực tế, các môn điều kiện thường giống nhau ở nhiều nghề. Đào tạo giáo viên hoàn toàn không phải đào tạo các chuyên gia toán, khoa học, ngôn ngữ học, văn học. Các nghề chủ yếu phân biệt nhau ở chuyên môn chứ không phải ở các điều kiện. Giáo viên Toán phải coi Toán là điều kiện để hành nghề dạy học, và các khoa học giáo dục mới là chuyên môn của nghề này, cho phép hành nghề dạy học.

Trong một số công trình nghiên cứu, chúng tôi đã mô tả nội dung và cấu trúc chung của năng lực nghề dạy học, hay năng lực nghề nghiệp của nhà giáo [2], [3], [5], [6]. Đó là cơ sở chủ yếu để phát triển chương trình đào tạo giáo viên mầm non, tiểu học và trung học cơ sở, mặc dù mỗi ngành học này rất khác nhau về các phần đào tạo điều kiện. Mô hình năng lực nghề nghiệp của nhà giáo được phản ánh khái quát trong hình dưới đây, bao gồm 4 năng lực cơ bản (Nguồn: Đặng Thành Hung (2017) [3, tr.16]). Trong mô hình này, mọi tiêu 
chí và minh chứng của năng lực nghề nghiệp nhà giáo đã được mô tả dưới dạng các năng lực thành phần. Chẳng hạn, về đạo đức nghề nghiệp và văn hóa nghề nghiệp không nói chung chung mà chỉ rõ năng lực thực thi đạo đức nghề nghiệp, năng lực thực thi văn hóa nghề nghiệp.

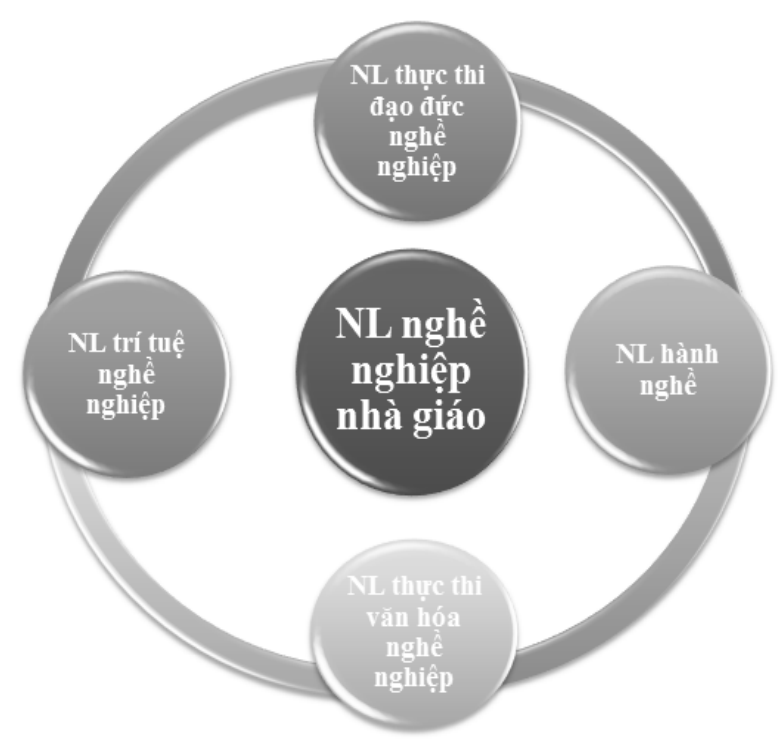

Hình 1: Mô hình năng lực nghề nghiệp nhà giáo

\subsubsection{Năng lục trí tuệ nghề nghiệp}

a) Tri thức môn học và hoạt động giáo dục ngoài môn hoc:

Tri thức và tư duy lí luận về chương trình môn học và khoa học tương ứng với môn học; Tri thức và tư duy lí luận về phương pháp bộ môn; Tri thức và tư duy lí luận về phương tiện, học liệu của môn học; Tri thức và tư duy lí luận về quản lí và tiến hành hoạt động giáo dục theo môn học.

b) Tri thức về con người và sụ phát triển người học (Sinh lí học, Tâm lí học, Giáo dục học, Xã hội học):

Tri thức và tư duy lí luận về sinh lí học và giải phẫu người; Tri thức và tư duy lí luận về tâm lí học giáo dục; Tri thức và tư duy lí luận về học tập và dạy học; Tri thức và tư duy lí luận về quản lí và tiến hành các hoạt động giáo dục ngoài môn học.

c) Tri thức về thông tin, môi truờng và điều kiện giáo duc:

Tri thức và tư duy lí luận về thông tin học đường; Tri thức và tư duy lí luận về môi trường của lớp học, trường học; Tri thức và tư duy lí luận về truyền thông giáo dục; Tri thức và tư duy lí luận về giáo dục gia đình và xã hội. d) Tri thức về phuơng pháp, phương tiện, công nghệ dạy hoc:

Tri thức và tư duy lí luận về ứng dụng phương pháp dạy học; Tri thức và tư duy lí luận về phương tiện dạy học và sử dụng phương tiện dạy học; Tri thức và tư duy lí luận về công nghệ thông tin và ứng dụng công nghệ thông tin trong quá trình giáo dụcvà quản lí giáo dục.

\subsubsection{Kũ năng nghề nghiệp hay năng lục hành nghề}

a) Nhũng kĩ năng nghiên cúu người học và việc học:

Kĩ năng quan sát người học và hành vi học tập; Kĩ năng đo lường những đặc điểm tâm-sinh lí của người học; Kĩ năng điều tra bằng các kĩ thuật thông thường; Kĩ năng tiến hành thực nghiệm khoa học; Kĩ năng thu thập và phân tích dữ liệu học tập.

b) Nhũng kĩ năng lãnh đạo người học và quản lí viẹc hoc:

Kĩ năng thuyết phục và hợp tác với người học; Kĩ năng phát biểu và giải thích ý tưởng cho người học; Kĩ năng khuyến khích, động viên người học; Kĩ năng tổ chức lớp và nhóm học tập; Kĩ năng quản lí thời gian và nguồn lực học tập.

c) Nhũng kĩ năng thiết kế dạy học và hoạt động giáo dục:

Kĩ năng thiết kế giáo trình, học liệu, bài học; Kĩ năng thiết kế hoạt động của người học; Kĩ năng thiết kế phương pháp và kĩ thuật dạy học; Kĩ năng thiết kế giáo trình, học liệu và phương tiện e-learning; Kĩ năng thiết kế môi trường học tập (hoặc môi trường hoạt động).

d) Nhũng kĩ năng dạy học và tác động giáo dục trục tiếp:

Kĩ năng giao tiếp và ứng xử trên lớp; Kĩ năng hướng dẫn, điều khiển, điều chỉnh hành vi học tập; Kĩ năng giám sát, kiểm tra, đánh giá quá trình và kết quả học tập; Kĩ năng sử dụng các phương tiện và công nghệ dạy học; Kĩ năng thực hiện các biện pháp và kĩ thuật dạy học cụ thể.

\subsubsection{Năng lực thực thi đạo đức nghề nghiệp}

a) Tình cảm và úng xủ đạo đức đối với nguời họ:

Thể hiện tình cảm đạo đức với người học trong mọi hoàn cảnh; Thể hiện sự trung thực và hành vi ứng xử hợp đạo đức với người học trong mọi hoàn cảnh; Thể hiện thái độ ân cần với người học bị thiệt thòi; Thực hiện những hành vi đạo đức giúp đỡ 
người học khi cần; Nhận thức sâu sắc quan hệ đạo đức với người học.

\section{b) Quan hệ đạo đức với đồng nghiệp và vói nghề:}

Thể hiện sự trung thực và quan hệ đạo đức đúng mực với đồng nghiệp trong mọi hoàn cảnh; Thể hiện tình cảm đạo đức thân thiện với đồng nghiệp; Thực hiện hành động đạo đức giúp đỡ đồng nghiệp khi cần; Thể hiện tình cảm đạo đức và thái độ yêu nghề, gắn bó với nghề; Thể hiện thái độ và hành vi đoàn kết, hợp tác trên cơ sở đạo đức.

c) Quan hệ và ứng xủ đạo đức với cộng đồng và gia đinh:

Tôn trọng các giá trị đạo đức của cộng đồng; Thể hiện hành vi ứng xử hợp đạo đức với cộng đồng; Thể hiện hành vi ứng xử hợp đạo đức với gia đình người học; Thể hiện tình cảm đạo đức đúng mực trong quan hệ với cộng đồng; Thực hiện tính trung thực trong quan hệ với cộng đồng và gia đình.

\section{d) Nguyên tắc đạo đức trong thục hiện nhiệm vụ:}

Thể hiện tính nguyên tắc trong các quan hệ đạo đức khi thực hiện nhiệm vụ nghề nghiệp; Thể hiện hành vi đạo đức trong các nhiệm vụ được giao; Tôn trọng nguyên tắc đạo đức trong thực hiện nhiệm vụ; Thể hiện tính trung thực trong thực hiện nhiệm vụ; Thể hiện nhận thức đúng và hành vi ủng hộ các giá trị đạo đức trong quan hệ công vụ.

\subsubsection{Năng lưc thưc thi văn hóa nghề nghiệp}

a) Phong cách cá nhân và phong cách su phạm:

Thể hiện phong cách cá nhân lịch sự, ngăn nắp, gọn gàng; Thể hiện phong cách sư phạm mẫu mực, đáng trọng; Thể hiện phong cách sư phạm thân thiện với mọi người; Thể hiện văn hóa hợp tác với mọi người; Thể hiện phong cách nhà giáo có tính chuyên nghiệp.

b) Học tập thường xuyên và guoong mẫu:

Bộc lộ việc học tập thường xuyên của mình trước mọi người; Thể hiện những kĩ năng học tập cá nhân; Thể hiện tính gương mẫu trong học tập; Thể hiện sự tiến bộ nhất định trong học tập; Thể hiện thái độ và hành vi ủng hộ việc học tập của mọi người.

\section{c) Nhận thức văn hóa xã hội:}

Thể hiện thị hiếu văn hóa lành mạnh, đẹp đẽ; Thể hiện tình cảm thẩm mĩ đúng đắn trong công việc; Thể hiện các kĩ năng cảm thụ văn hóa, nghệ thuật đúng đắn; Thể hiện hành vi văn hóa, trang phục, ngôn ngữ chỉnh tề; Thể hiện nhận thức đúng về các giá trị văn hóa dân tộc.

\section{d) Kĩ năng xã hội:}

Kĩ năng nhận thức các quan hệ xã hội; Kĩ năng nhận thức và đánh giá các sự kiện, hiện tượng xã hội; Kĩ năng giao tiếp xã hội trong những hoàn cảnh cần thiết; Kĩ năng giải quyết vấn đề xã hội nảy sinh trong công việc; Kĩ năng thích ứng xã hội trong khi thực hiện nhiệm vụ.

\subsection{Tổ chức chương trình và hoạt động đào tạo}

Chương trình và hoạt động đào tạo cần được tổ chức theo 4 năng lực trên, trọng tâm là năng lực hành nghề mà cốt lõi là những kĩ năng làm việc trực tiếp. Chỉ riêng phần năng lực liên quan đến môn học (Toán, khoa học, ngôn ngữ học...) có thể phải có cấu trúc bộ môn kết hợp với cấu trúc chủ đề, dự án, đề tài, bài tập... còn cả 4 năng lực đều chủ yếu dựa vào trải nghiệm, rèn luyện thực tế. Phần môn học trong đào tạo giáo viên mầm non, tiểu học không cần tổ chức môn học, mà thực hiện qua các chủ đề, dự án, đề tài nghiên cứu, bài tập seminar và tự học. Lâu nay chúng ta lãng phí rất nhiều trong dạy học toán, ngôn ngữ học, văn học, các khoa học tự nhiên và khoa học vật chất. Trên thực tế, giáo viên mầm non và tiểu học không cần học nhiều và khó như vậy về các mảng này, chỉ cần trình độ trung học phổ thông là đủ. Sinh viên chỉ cần tự mình nghiên cứu các chủ đề toán, khoa học, ngôn ngữ... sau này mình phải dạy trong chương trình giáo dục mầm non và tiểu học. Họ cần đào tạo nhiều và chủ yếu về mảng sư phạm, nhất là kĩ năng hành nghề. Còn trong đào tạo giáo viên trung học cơ sở, phần môn học có thể khó hơn và được thiết kế, thực hiện theo bộ môn, song cũng không cần khó và nhiều như lâu nay vẫn làm.

Như vậy toàn bộ đào tạo phần môn học chỉ chiếm 1/5 (Mầm non, Tiểu học) đến 1/4 (Trung học cơ sở) tổng thời lượng đào tạo, và được thực hiện tại cơ sở đào tạo. Thời lượng còn lại tập trung cho các năng lực khác, ngay từ đầu, bắt đầu từ năng lực thứ 2 trong năng lực trí tuệ nghề nghiệp cho đến hết, và chủ yếu được thực hiện tại trường mầm non, phổ thông, cũng như qua các hoạt động thực hành tại trường sư phạm. Không dạy Tâm lí học, Giáo dục học theo hình thức nặng về lý thuyết, mà sinh viên sẽ học tập qua các dự án, đề tài nghiên cứu, semina khoa học, bài tập thực hành... với $4 / 5$ hoặc $3 / 4$ thời lượng đào tạo được dành cho trải nghiệm nghề nghiệp, rèn luyện kĩ năng hành nghề và năng lực thực thi đạo đức, văn hóa nghề nghiệp ngay tại trường mầm non, tiểu học và trung học cơ sở. Tức là 
sinh viên chủ yếu phải ở trường mầm non, tiểu học và trung học cơ sở để học hỏi, rèn luyện. Ngoài quỹ thời gian đó, các em phải tự học, tự nghiên cứu.

Để làm được như thế cần phải thay đổi nhận thức lí luận về phát triển chương trình, về phát triển phương pháp dạy học, về quản lí đào tạo và đảm bảo chất lượng đào tạo. Cần phát triển rất nhiều và đa dạng các giáo trình, học liệu và các tư liệu khoa học khác để tham khảo tương ứng với các tín chỉ. Thiết kế tín chỉ theo hệ thống năng lực (4 mảng chính) và các kĩ năng cốt lõi thành phần của chúng. Tỉ trọng tự học của mỗi tín chỉ luôn là $4 / 5$ hoặc $3 / 4$. Cơ cấu của học liệu cũng phải thay đổi sao cho thuận lợi cho tự học và quản lí đào tạo theo chế độ tín chỉ. Hạt nhân của mỗi tín chỉ luôn là kĩ năng, tri thức chỉ là tối thiểu đủ để hỗ trợ việc học kĩ năng đó. Sinh viên học lí thuyết và các tri thức mở rộng qua con đường tự học, nghiên cứu đề tài giáo dục, làm tiểu luận, tham luận hội nghị khoa học, dự hội thảo, tham gia dự án...

\section{3. Đánh giá tốt nghiệp}

Nếu chương trình và hoạt động đào tạo như vậy thì đánh giá tốt nghiệp cần chuyển hẳn sang đánh giá kĩ năng, ít nhất là những kĩ năng hành nghề. Tức là đánh giá các kĩ năng nghiên cứu, các kĩ năng thiết kế dạy học, các kĩ năng tiến hành dạy học và các kĩ năng lãnh đạo, quản lí học tập. Muốn làm được điều này, cần chuẩn bị chu đáo và xác định rõ lộ trình thi tốt nghiệp toàn bộ những kĩ năng hành nghề. Các đánh giá khác chỉ có ý nghĩa tham khảo. Bất kể nghề nào cũng thi tốt nghiệp bằng kĩ năng hành nghề, ví như nghề sáng tác âm nhạc hay hội họa phải thi tốt nghiệp bằng bản nhạc hay bài hát, bằng tranh hay tượng, nghề điện ảnh phải thi tốt nghiệp bằng những bộ phim, nghề thợ hàn phải thi kĩ năng hàn... Chỉ riêng nghề dạy học lâu nay lại thi những thứ không phải kĩ năng nghề cho nên mới không đạt được tính chuyên nghiệp.

Các hình thức đánh giá tốt nghiệp qua đánh giá kĩ năng hành nghề bao gồm: 1/ Đánh giá các sản phẩm hoạt động của sinh viên: bài thực hành, dự án, kết quả nghiên cứu, báo cáo semina, kết quả làm bài tập, kết quả luyện tập thiết kế dạy học, kết quả giờ dạy thực hành .v.v. thường xuyên trong quá trình đào tạo; $2 /$ Đánh giá kĩ năng cụ thể trực tiếp khi sinh viên trình diễn, tức là gần giống thi vấn đáp, nhưng nội dung là kĩ năng. Ví dụ, sinh viên rút được phiếu thi là "Thiết kế một bài học toán theo lí thuyết kiến tạo ở tiểu học", hay "Kĩ thuật tổ chức một trò chơi phát triển nhận thức ở mẫu giáo lớn".v.v. thì sinh viên đó phải trình diễn kĩ năng tương ứng ngay trước mắt các giám khảo.

Khi qui định thi tốt nghiệp bằng kĩ năng thì tự điều đó đã là động lực to lớn giúp sinh viên tập trung rèn luyện nghề nghiệp. Ngay cả khi nhiều giảng viên không dạy được kĩ năng thì cũng không đáng lo ngại. Vì phải thi kĩ năng theo chuẩn đầu ra, sinh viên sẽ tìm mọi cách để học kĩ năng, chịu khó xuống trường phổ thông, mầm non giao lưu với các nhà giáo, các chuyên gia, chia sẻ với bạn bè, rèn luyện trong thực tiễn môi trường sư phạm. Đánh giá thế nào thì việc dạy và học sẽ phải điều chỉnh theo như thế. Đánh giá qua kĩ năng là biện pháp hữu hiệu để khắc phục tệ nạn sao chép, học vẹt và gian lận trong thi cử.

Đánh giá tốt nghiệp qua năng lực hành nghề là hình thức trực tiếp kiểm định chất lượng đầu ra một cách chính xác nhất. Sinh viên tốt nghiệp hoàn toàn đủ năng lực dạy học cơ bản và năng lực đó cho phép các em thích ứng nhanh với nhiệm vụ thực tế ở nhà trường mầm non, phổ thông. Điều đó mới đúng với bản chất của giáo dục nghề. Giáo viên hoàn toàn không phải nhà toán học, nhà sinh vật học, nhà sử học, nhà vật lí học, nhà ngôn ngữ học, nhà văn...mà là nhà giáo dục. Từ cấp trung học cơ sở trở xuống, sinh viên sư phạm không cần phải học quá nhiều những kiến thức hàn lâm không phục vụ trực tiếp cho việc hình thành năng lực nhà giáo theo yêu cầu ở mỗi cấp học. Chương trình phải hướng tới việc hướng dẫn người học biết cách tiếp cận các nguồn tài liệu, lựa chọn những kiến thức căn bản, cốt lõi hướng vào việc trau dồi phẩm chất đạo đức, phát triển năng lực hành nghề sư phạm và không ngừng hoàn thiện qua việc tự học suốt đời.

\section{Kết luận}

Việc đổi mới giáo dục hiện nay đang đặt ra yêu cầu đổi mới từ tư duy lí luận đến thực tiễn đào tạo giáo viên. Cần có những thay đổi triệt để hơn trong phát triển chương trình và tổ chức hoạt động đào tạo dựa trên nhận thức lí luận đúng đắn về nghề dạy học và thực tiễn giáo dục mầm non, tiểu học, trung học cơ sở đang đòi hỏi. Thay đổi đó chủ yếu căn cứ vào quan niệm năng lực nghề nghiệp nhà giáo (năng lực nghề dạy học), trong đó hạt nhân là các kĩ năng hành nghề, và con đường học tập, rèn luyện bằng trải nghiệm cũng như đánh giá tốt nghiệp thông qua kĩ năng hành nghề của sinh viên. Giáo trình, học liệu cần phải phong phú và tập trung vào phát triển năng lực nghề dạy học. 


\section{TÀI LIỆ THAM KHẢO}

1. Đặng Thành Hưng, "Năng lục và giáo dục theo tiếp cận năng lực", Tạp chí Quản lí giáo dục, số 43 tháng 12/2012;

2. Đặng Thành Hưng, "Kĩ năng dạy học và tiêu chí đánh giá", Tạp chí Khoa học giáo dục, số 88 tháng 01 , 2013, tr. 5-9;

3. Đặng Thành Hưng, "Mô hình năng lực nghề nghiẹpp của nhà giáo hiện đại”, Tạp chí Khoa học dạy nghề, số 28-29, tháng 1+2, 2016, tr. 14-18;

4. Nguyen Khai Hoan, Tan Trao University (Vietnam), Current state of pedagogical professional training for college students specializing in primary educaition, Journal of psychology Vietnam Academy of Social Sciences, số 8, 8/2016;

5. Nguyễn Khải Hoàn, Đoàn Thị Cúc, "Truoòng đại hoc dịa phuong với việc phát triển mô hình đào tạo giáo viên đáp úng yêu cầu đổi mới giáo dục phổ thông”, Tạp chí Giáo dục,số đặc biệt, 10/2016;

6. Nguyễn Khải Hoàn, Đoàn Thị Cúc, "Phát triển đội ngũ giáo viên phổ thông tù góc độ phát triển chuoongtrình đào tạo nghiệp vu su pham trong các co sở đào tạo giáo viên", Kỷ yếu Hội thảo khoa học quốc tế "Phát triển đội ngũ giáo viên đáp ứng yêu cầu đổi mới giáo dục phổ thông”, Nxb Đại học sư phạm, $12 / 2016$.

\section{Curriculum for teachers focusing on competence}

Dang Thanh Hung; Nguyen Khai Hoan

\section{Article info}

Recieved:

06/02/2018

Accepted:

10/3/2018

\section{Keywords:}

Competence;

Curriculum; teacher training.

\section{Abstract}

The problem of developing curriculum for nursery, primary and secondary teachers is not new in pedagogical schools. However, the teacher training system still remain a lots of problems, especially the post-training professional competence is not clear. This article helps to clarify the issues of teaching competence, the orientation of program organization and training activities focusing on competence. 